\title{
A COMPARATIVE ANALYSIS OF APPLIED LINGUISTICS AND ECONOMIC PSYCHOLOGY RESEARCH ARTICLES: VERB TENSE IN CONCLUSION SECTION
}

\author{
Tania Laghari \\ Assistant Professor, Department of English, Shaheed Benazir Bhutto University, Shaheed \\ Benazirabad \\ Tania.laghari@sbbusba.edu.pk
}

\begin{abstract}
Tahreem Akhter
Language Academy, Faculty of Social Sciences and Humanities, Universiti Teknologi Malaysia, Jalan Sultan Yahya Petra, Kuala Lumpur tahreem@graduate.utm.my
\end{abstract}

\section{Ruqia Bano Mastoi}

Lecturer, Department of English, Shaheed Benazir Bhutto University, Shaheed Benazirabad/

Ph.D. Scholar, Universiti Teknologi Malaysia, Malaysia

Ruqiabano.mastoi@sbbusba.edu.pk

\begin{abstract}
Conclusions to research articles are considered an important part because they draw conclusions based on the findings, discuss pedagogical and policy implications, and make future recommendations. The paper looks at an analysis of the rhetorical structure of conclusion sections of journal articles. Despite the extensive exploration of the topic, it has not received much attention regarding the appropriate use of verb tense in conclusion sections. To achieve this end, a corpus of 50 research articles from Applied Linguistics and Economic Psychology was compiled and examined based on Yang and Alison's (2003) model of move structure of the conclusion section. The findings of this study revealed that Move 2 (Evaluating the study) and Move 3 (Deductions from the research) are found to be obligatory moves in both sets of data. As far as the tense pattern in the moves is concerned, the frequency measure showed a slight distinction in the usage of verb tense; however, no significant difference between both disciplines was calculated. Furthermore, the results showed that simple present tense is the most frequently used tense in all the moves of two corpora. The findings of this study may prove helpful for ESL students regarding the preference of tense patterns while composing conclusion sections.
\end{abstract}

Keywords: Verb Tense, Conclusion Section, Rhetorical Structure, Research Articles, Academic Writing

\section{INTRODUCTION}

Academic writing like Research Articles is often considered to be a significant source of communication in academic discourse communities. Written academic discourse is analyzed and appreciated from different angles due to its incredible popularity as a separate genre. Thomas and Hawes (1994) have said that research articles as an example of academic writing is identified by "a recognizable communicative purpose and by the presence of characteristic features with standardized form, function, and presentation that are part of its general conventions" (p. 131). Thus, effective research paper writing not only depends on language proficiency but also the knowledge writers possess about rhetorical structures and conventions mutually recognized by the academic discourse community.

Nowadays, genre analysis is receiving widespread attention. Genre analysis is a valuable tool for unraveling and connecting a genre's linguistic features to its function and purpose. It enables the identification of genre-specific movements and linguistic features. The term "genre analysis" refers to the way texts are structured and organized (Hopkins \& Dudley-Evans, 1988). The genre analysis of RAs was motivated by pedagogical concerns, a factor that is becoming increasingly important as the number of research writers grows rapidly. 
Since Swales's (1990) work on the rhetorical structure of research articles, extensive research on the move analysis of various components of academic research articles has been conducted. In effect, move analysis is a genre-based approach that authors use to investigate the structure of research articles. According to Bhatia (1993), each move has a characteristic that is unique to a genre; thus, understanding the function of each move and the overall structural pattern of the text enables a better understanding of a particular genre. Much research is done regarding move analysis in different sections of research article (Introduction, Methods, Results, Discussion, and Conclusion) following several frameworks (Samraj, 2002; Bruce, 2008; Brett, 1994; Peacock, 2002; Aslam \& Mehmood, 2014). Thus, it is important to note that the move analysis approach has grasped the immense attention of a number of authors while analyzing the structure of different sections of research articles.

However, not much focus has been paid on the conclusion section as it seemed to have been overlooked by researchers because of the blurred boundary between discussion and conclusion section. Although a couple of studies on the conclusion section only focused on the move analysis and present various move models, little attention has been paid on the cross-disciplinary distinction in the rhetorical structure of the said section. Moreover, not many studies have been witnessed in the domain of linguistic realizations especially verb tense in structural units of conclusion sections. In effect, verb tense also plays particularly important role in effective writing, thus it becomes the focus of the current study. To our limited knowledge, this is perhaps the first attempt in investigating verb tense realizations in the rhetorical structure of conclusion sections.

The main aim of this study was to examine the rhetorical structure of research article conclusions in the fields of Applied Linguistics and Economic Psychology. Furthermore, this study also analyzed whether there is any variation regarding the usage of verb tense in the rhetorical organization of conclusion sections of two corpora. The process of analyzing verb tense usage is based on the conclusion section's move structure. As this is the first attempt at analyzing verb tense rhetorical conventions, the researcher concentrated on the use of verb tense in specific moves in the conclusion section in two disciplines. The study sought to address the following research questions:

a) How are the rhetorical moves employed in the conclusion sections of Applied Linguistic and Economic Psychology RAs?

b) How are verb tenses employed within the rhetorical structure of conclusion sections of RAs in Applied Linguistics and Economic Psychology?

c) Is there any significant difference in Applied Linguistic and Economic Psychology RA conclusions in terms of moves and verb tense usage?

\section{LITERATURE REVIEW}

Presently, researchers have been busy in studying various forms of academic writing to recognize their rhetorical structures and language characteristics (Kanoksilapatham, 2013; Li, Franken, \& Wu, 2020; Darabad, 2016; Zand-Moghadam \& Mihami, 2016; Fatma \& YAĞIZ, 2020). Generic features like moves and steps in different discourse types are also studied by a large number of linguists. Moves and steps are used by authors to organize the whole information of their research writing. Move analysis is a significant part of genre analysis (Swales, 1990 \& 2004). Researchers employ move analysis in order to recognize the generic structure and rhetorical organization in different discourse texts. Moving forward, a move is a functional unit that can be acknowledged by a clause or several propositions. It can be as long as several paragraphs to a single sentence or sometimes even half a sentence. Some moves are obligatory, while others are optional. A move is further divided into steps that may or may not be present in a particular discourse.

Numerous studies have examined the structural organization of various sections of RAs, including the Introduction (Samraj, 2002; Swales, 1990), the Methods (Bruce, 2008; Harwood, 2005), the Results (Williams, 1999, Yang and Allison, 2003), and all four sections (Kanoksilapatham, 2005; Nwogu, 1997; Posteguillo, 1999). There is less emphasis on the conclusion section of the RA because it typically appears to be a component of the discussion section of a RA. According to Weissberg and Buker (1990), the final section of RA is "typically titled discussion (but) occasionally referred to as conclusions" (p.161). The pioneering work in this sub-genre is Yang and Allison's (2003) study of the conclusion sections of RAs in applied linguistics. They proposed three steps (see Table 1) for conducting a generic analysis of the conclusion section of research articles. 
Another important study was conducted by Moritz et al (2008). In their cross-linguistic study, Moritz et al., (2008) investigated the rhetorical structure of the conclusion section in Applied Linguistic RAs written by Portuguese L1, English L2, English L2 authors. The results of their study revealed six different moves that include 'Restating the introductory statement', 'Consolidating the research space', Summarizing the study', 'Commenting on results', Evaluating the study' and 'Making deductions from the research'. Additionally, the results indicated that M6 (Drawing conclusions from the research) was the most frequently occurring move. Aslam and Mehmood (2014) conducted a cross-disciplinary study in which they analyzed the conclusion sections of RAs in Natural and Social Sciences written by Pakistani authors. Their study sought to ascertain common movement patterns in conclusion sections across a variety of disciplines. According to their findings, Move 1 (summarizing the study) was the most frequently occurring move in conclusion sections of both disciplines. Moves 2 and 3 were discovered to be optional in both data sets.

Similarly, to my knowledge, relatively few but significant studies on the rhetorical structure of conclusion sections have been conducted across a variety of disciplines. Ghafanzafri et al., (2016) examined the rhetorical organization of conclusion sections in two disciplines, English language teaching and nursing, using Yang and Allison's (2003) move model. This study discovered that there was no significant difference in the rhetorical organization of the two data sets. Similarly, Reza Adel and Moghadam (2015) analyzed the rhetorical structure of the conclusion sections of 30 RAs from three distinct disciplines: applied linguistics, psychology, and Persian literature. Additionally, the findings of their study indicated that, despite some cross-disciplinary and cross-linguistic variation regarding Move 2, no significant variation in conclusion sections was discovered. The current study shows distinction from other related studies in a way that it not only offers the rhetorical analysis of conclusion sections of Applied Linguistics and Economic Psychology research articles but also highlights the appropriate deployment of verb tense in different moves of conclusion section.

\section{Verb tense}

It is often believed in English academic discourse that it is due to verb tense change that a piece of information experiences changes in status from being a scientific notion to a finding in the research project. As indicated in textbooks and style guides, if student writers who desire to establish a recognizable position in the discourse community, he is supposed to learn conventional usage of verb tense in different parts of a text. As Taylor (1989: p.150) notes "there are certain conventions about the use of tenses - especially past and present-in academic writing which are not intuitively obvious". That is why verb tense conventions are set down by writers and editors in scientific English. Swales and Feak (1994) stressed the truth based on the knowledge published in many academic papers that verb tense conventions are not rigidly followed by authors in real life. They are considered to possess rhetorical power in the deployment of verb tense usage.

A profound number of researches stress suitable deployment of verb tense in academic writing. In Anglophone countries, the proper use of verb tense is an essential part of academic writing tradition. Not only instilled by writing manuals but also by expert members of the discourse community, verb tense conventions are needed to be mastered by student writers. Nevertheless, nonnative speakers have to take extra pain in learning to use appropriate verb tense in academic writing. As highlighted by Hinkel (1997), proper use of past tense is considered to be especially complicated. The effect of the mother tongue is another problem regarding the deployment of proper verb tense in academic writing for non-native speakers.

Outside this area of research, quite a few studies have been carried out investigating the tense usage in various rhetorical sections of academic discourse (Salager-Mayer, 1992; Tseng, 2011; Dastjerdi et al., 2017; Öztürk, 2019). All these studies provided rather insightful results regarding the use of verb tense to clarify the structural units of the aforementioned sections. Salager-Meyer (1992) examined how abstracts of medical journal articles conveyed meaning in terms of tense application. Salager-(1992) Meyer's study found that the past, present, and present perfect tenses were the most frequently used tenses in the study's texts' various rhetorical units. Salager-Meyer (1992) noted that the examined texts employed a total of seven rhetorical devices. Salager-Meyer (1992) found that the past tense was the most frequently used tense in the results, methods, and purpose sections of the investigated texts. However, the past tense was used less frequently in data synthesis and conclusion moves because, according to Salager-Meyer (1992), the data presented in these moves are timeless and generalizations. 
Fallahi and Erzi (2003) examined the proper use of tense patterns in the rhetorical structure of Discussion sections of language teaching RAs. Their analysis revealed that 95 percent of all tenses used in the 'information' move were present tense. This preference may be due to the move's communicative purpose, as information moves are used to convey facts and accepted knowledge within the discipline; they are presented in the present tense. In effect, while composing moves, communicative purpose and tense application are inextricably linked. Nonetheless, the past tense is frequently used in the 'unexpected outcome' move, which was possible due to the non-generic nature of prior results. Apart from the 'procedure' move, which was presented in the past tense, the majority of the other moves in Fallahi and Erzi's (2003) study were presented in the present tense.

Dastjerdi et al., (2017) conducted a more recent study in which they examined the use of tenses in obligatory rhetorical units (moves and steps) in twenty master's theses in the hard sciences written by ESL students. They used a mixed method of quantitative and qualitative approaches to investigate tense usage in corpus-required rhetorical units. The contextual analysis revealed that the simple present tense was the most frequently used tense (66.03 percent), followed by the simple past tense (28.14 percent).

In the above discussion, we have seen that verb tense usage is discussed in almost every section of research article i.e., abstracts, introduction, discussion; however, its appropriate usage in the rhetorical structure of the conclusion section is yet to be discussed. We hope that our research will fill the gap and provide insight into understanding academic writing conventions.

\section{METHODOLOGY}

\section{Data}

In the present research, a corpus of 50 published research articles was used. It was further divided into two sub-corpora: one set consists of 25 Applied Linguistics (AL) RAs and the other set includes 25 Economic Psychology (EP) RAs. All these articles were published in the years 2017 and 2018 in high impact factor journals, i.e., for Applied Linguistics: Journal of English for Specific Purposes (Elsevier); and Economic Psychology: Journal of Economic Psychology. Nwogu's (1997) three criteria for corpus selection, namely, representativeness, reputation, and accessibility were also kept in mind while selecting the corpus of the present research. The present corpus was mostly representative of research articles genre in terms of content regarding the disciplines of AL and EP. As far as the criterion of reputation is concerned, both these journals are peer-reviewed and have good international stance. And also both these journals are easily accessible to the researchers. The articles for the current corpus were also selected on the basis of the language of the text (in this case academic English) and possible audience (international academics). Another thing that should also be made clear is that the research articles selected in the present study followed the IMRD (IntroductionMethods-Results-Discussion) format with a separate section of the conclusion. Therefore, research articles with an integrated section of Discussion and Conclusion were opted out as they do not fall into the purpose of this study. Also, all the research articles in both datasets were codified in two groups to make it easy to identify and track the analysis like AL1-AL25 (Applied Linguistics) and EP1-EP25 (Economic Psychology).

\section{Data Analysis}

In the current study, a mixed-method approach is used. Creswell (2009) argues that a mixed-methods approach combines the strengths of qualitative and quantitative approaches to adequately address the complexity of a social phenomenon when neither qualitative nor quantitative approaches alone can adequately address the complexity of the social phenomenon. Hence, the present research is both quantitative and qualitative in nature. The occurrences of verb tense were counted and doublechecked manually, while text analysis of the RAs was carried out qualitatively. Furthermore, the researcher first counted all the occurrences of moves for rhetorical structure quantitatively in the data set. Afterward, each move was further examined qualitatively. There were two stages to carry out the analysis of the data set. The identification of all the moves was done along with their communicative purpose, their pattern and order to know if any move is missing or repeated in the first stage; secondly, we categorized these moves as obligatory or optional according to their frequency. Every occurrence of each move was calculated in order to find out whether a move is obligatory or optional. Therefore, the cut-off frequency for the classification of the moves was set as $60 \%$ for the present study (Kanoksilapatham, 2005). Following this point, if a move occurred in $100 \%$ of conclusion 
sections it would be deemed as obligatory. If a move was present in 60\%-99\% of research articles, it is considered as conventional, and if less than $60 \%$ conclusion sections employed a move, it will be regarded as optional. Lastly, on the basis of their frequency count, substantial variations regarding the preference of tense pattern in both disciplines were examined.

\section{Instrument}

Different models have been used for the analysis of the generic organization of the final segment (conclusion sections) in RAs based on the communicative purpose of the conclusion section. However, the data analysis instrument used in this study is Yang and Allison's (2003) model for move analysis. We adopted this model because it seemed to suit our findings from the corpus. This model is adopted for the detailed examination of the move-step organization of conclusion sections in this study. All moves presented in the said model were set out in Table 1.

Table No. 1 Proposed model by Yang and Allison (2003)

\begin{tabular}{ll}
\hline Move 1 & Summarizing the study \\
\hline Move 2 & Evaluating the study \\
Step 1: & Indicating significance/advantage \\
Step 2: & Indicating limitations \\
Step 3: & Evaluating methodology \\
Move 3 & Deductions from the research \\
Step 1: & Recommending further research \\
\hline Step 2: & Drawing pedagogic implications \\
\hline
\end{tabular}

Percentage of moves and steps was calculated as

Percentage $=$ Number of moves or steps $/$ Total number of conclusions X 100

\section{Analysis of Moves}

The researcher first carried out the move analysis by identifying each move separately in both corpora. It should also be mentioned that although a sentence is considered as the fundamental unit of move analysis, an attempt was made to calculate a move in both clauses and phrases as well. However, the tense count at the phrasal level was excluded. After all the moves in conclusion sections of both corpora were identified and coded separately, the data was again analyzed two weeks later to measure the reliability of the analysis. Inter-coder reliability test was used to ensure the validity and reliability of the classification of moves and steps. Another rater was asked to go through the sample and the results were compared. After a thorough discussion about the disagreements between the raters, the final agreement was reached. As far as intra-rater reliability is concerned, the text was revisited after two months by the first author to re-analyze the coding of moves and steps.

\section{Analysis of Verb Tense}

The researcher used two verb tenses to analyze conclusion sections following Tseng (2011): present (Simple and perfect) and past tense. The analysis of the appropriate deployment of verb tense was carried out through different procedures. The verb tense of each sentence was considered to be the verb tense of that move. As mentioned above, the analysis of verb tense is done with the help of move analysis; it was also considered whether the move is present in a phrase or a sentence. If the move was identified in a phrase, the verb tense in that particular move was not counted, while the verb tense of the move present in one or two sentences was counted and included in the data. Having collected the data, the frequency of each move and verb tense was counted. In the end, the total number of occurrences of moves and verb tense in Applied Linguistics RAs was calculated and compared with the total number of moves and verb tense in Economic Psychology RAs.

\section{RESULTS}


The current study examines the appropriate use of verb tense in the conclusion sections of 50 published research articles [25 from the field of Applied Linguistics and 25 from the field of Economic Psychology]. As previously stated, because our analysis is based on the move structure of the conclusion section, the study must first analyze the conclusion section's rhetorical structure. To accomplish this, all conclusion sections were examined to ascertain their generic structure. We followed Yang and Allison's (2003) model for conclusion section move analysis in doing so. Additionally, the researcher manually tagged all instances of moves in the corpus. To accomplish this, the results will be presented in the order of the aforementioned research questions.

Research question 1: How the rhetorical moves are employed in the conclusion sections of Applied Linguistic and Economic Psychology RAs?

The first research question sought out the overall occurrence and distribution of moves and steps in the conclusion sections of Applied Linguistics and Economic Psychology RAs. Table 2 shows the overall frequency and distributions of moves and steps in the corpora.

Table No. 2 Overall frequency and percentage of move and steps in conclusion sections of AL RAs.

\begin{tabular}{lll}
\hline Moves and Steps & Raw Frequency $\mathbf{( N = 2 5 )}$ & Percentage (100\%) \\
\hline M1: Summarizing the study & 23 & 92 \\
M2: Evaluating the study & 20 & 80 \\
S1: Indicating significance/advantage & 18 & 72 \\
S2: Indicating limitations & 12 & 48 \\
& & 56 \\
S3: Evaluating methodology & 14 & 76 \\
M3: Deductions from the research & 19 & 68 \\
S1: Recommending further research & 17 & 56 \\
\hline S2: Drawing pedagogic implications & 14 & \\
\hline
\end{tabular}

Consistent with Yang and Allison's (2003) study, the results indicate a high prevalence of Move 1 (Summarizing the study) in the current sub-corpus. Except for two articles, all appear to have made use of the summarizing move. Additionally, the results indicated that the summarizing move was used as the initial move in the majority of articles. The authors appeared to prefer beginning their conclusion sections by emphasizing the study's objectives and major findings. According to Table 2, there is a similarity in the frequency of use of Move 2 (Evaluating the study) and Move 3 (Deductions from the research) in the conclusion section of Applied Linguistics, which were used at an 80 percent and 76 percent rate, respectively. Additionally, the analysis revealed that linguists followed all steps necessary to accomplish Moves 2 and 3.

Table No. 3 Overall frequency and percentage of move and steps in conclusion sections of EP RAs.

\begin{tabular}{lll}
\hline Moves and Steps & Raw Frequency $\mathbf{( N = 2 5 )}$ & Percentage (100\%) \\
\hline M1: Summarizing the study & 25 & 100 \\
& 19 & 76 \\
M2: Evaluating the study & 19 & 76 \\
S1: Indicating significance/advantage & & 64 \\
S2: Indicating limitations & 16 & 76 \\
& & 72 \\
S3: Evaluating methodology & 19 & 64 \\
M3: Deductions from the research & 18 & 24 \\
S1: Recommending further research & 16 & \\
S2: Drawing pedagogic implications & 6 & \\
\hline
\end{tabular}


Like the section above, the authors in Economic Psychology RAs tend to open the conclusion sections of their study with the summarizing move. Also, it is found to be the most frequent move as it was detected in all the Economic Psychology articles. As is reported in Table 3, Move 2 (Evaluating the study) was employed in $76 \%$ RAs, whereas Move 3, deductions from the research, was found in $72 \%$ of the articles. A notable finding, according to Table 3, is the low preference of Step 2 (Drawing pedagogic implications) of Move 3 occurring with the frequency of only $24 \%$ in the corpora. Therefore, the results clearly imply that Economic Psychology authors preferred to realize Move 3 by recommending future directions (Step 1) more than drawing pedagogic implications (Step 2).

Research question 2: How are verb tenses employed within the rhetorical structure of conclusion sections of RAs in Applied Linguistics and Economic Psychology??

According to research question 3, the overall frequency and percentage of verb tense in Moves and steps of conclusion sections of both data sets was computed. The total distribution of verb tense in Applied Linguistics conclusions is presented in Table 4.

Table No. 4 Overall frequency and percentage of verb tense in structural units of AL subcorpus.

\begin{tabular}{lllllll}
\hline Moves & PT & & PAT & PP & \\
\hline & F & P & F & P & F & P \\
M1 & 46 & 25.6 & 10 & 5.5 & 14 & 7.8 \\
M2 & 53 & 29.6 & 19 & 10.6 & 9 & 5.02 \\
S1 & 26 & & 5 & & 1 & \\
S2 & 15 & & 10 & & 3 & \\
S3 & 12 & & 4 & & 5 & \\
M3 & 20 & 11.1 & 5 & 2.7 & 3 & 1.6 \\
S1 & 10 & & 0 & & 1 & \\
S2 & 10 & & 5 & & 2 & 14.4 \\
Total & 119 & 66.4 & 34 & 18.9 & 26 & \\
\hline
\end{tabular}

Note: percentage is obtained by dividing the raw frequency with total frequency of all three tenses

As is reported in Table 4, the most preferred tense in Applied Linguistics sub-corpus is simple present tense occurring with a total frequency of $66.4 \%$. The results also revealed that the highest frequency of simple present tense was found in evaluating the study move (about 29.6\%). While past tense only seemed to be preferred in Move 1 (Summarizing the study) and Move 2 (Evaluating the study) with the occurrence of $5.5 \%$ and $10.6 \%$. As can be seen in Table 4, the present perfect tense is the least preferred tense in the rhetorical structure in Applied Linguistics RAs.

As far as Economic Psychology conclusions are concerned, the clear picture of frequency distribution and percentage of tense pattern in Structural units of Economic Psychology conclusions is set out in Table 5 .

Table No. 5 Overall frequency and percentage of verb tense in EP sub-corpus

\begin{tabular}{lllllll}
\hline Moves & PT & & PAT & PP & \\
\hline & F & P & F & P & F & P \\
M1 & 71 & 31.1 & 9 & 3.9 & 5 & 2.1 \\
M2 & 76 & 33.3 & 22 & 9.6 & 1 & 0.4 \\
S1 & 20 & & 2 & & 0 & \\
S2 & 27 & & 13 & & 0 & \\
S3 & 29 & & 7 & & 1 & - \\
M3 & 44 & 19.2 & 0 & -- & 0 & \\
S1 & 22 & & 0 & & 0 & \\
S2 & 22 & & 0 & & 0 & 2.6 \\
Total & 191 & 83.7 & 31 & 13.5 & 6 & \\
\hline
\end{tabular}

Analysis of verb tense in the conclusion section of Economic Psychology subcorpus revealed the high preference of present tense by the authors of Economic Psychology RAs (Table 5). As can be seen in the Table above, authors were less inclined to draw conclusions of the study in past tense or 
present perfect tense. On closer examination, it can be seen that Move 2 (Evaluating the study) displayed the highest frequency of present tense (about 33.3\%). In effect, the frequency of present tense in Move 1 (Summarizing the results) and Move 3 (Deductions from the research) occupied second and third place in Economic Psychology corpora (31.1\% and 19.2\% respectively). Quite interestingly, it is also found that authors of Economic Psychology RAs did not seem to prefer past tense or present perfect tense to clarify Move 3, deduction from the research and preferred to present future recommendations and pedagogic implications in the simple present tense only.

Research question 3: Is there any significant difference in Applied Linguistic and Economic Psychology RA conclusions in terms of moves and verb tense usage?

Relating the variation between conclusion sections of RAs in both sets of data, the results of this analysis unveiled a number of interesting resemblance and distinction in Applied Linguistics and Economic Psychology disciplines. As far as the rhetorical structure is concerned, both the data sets used Move 1 (Summarizing the results) more than the other two moves. The overall distribution of moves and steps in the conclusions of both disciplines is set out in Table 6.

Table No. 6 The comparison of structural moves in the conclusions of AL and EP corpora.

\begin{tabular}{ccccc} 
Moves & \multicolumn{2}{c}{$\begin{array}{c}\text { Applied } \\
\text { Linguistics }\end{array}$} & \multicolumn{2}{c}{$\begin{array}{c}\text { Economic } \\
\text { Psychology }\end{array}$} \\
\cline { 2 - 5 } M1: Summarizing the results & $\mathrm{F}$ & $\mathrm{P}$ & $\mathrm{F}$ & $\mathrm{P}$ \\
\hline M2: Interpreting the results & 23 & 92 & 25 & 100 \\
\hline S1: Indicating significance/advantages & 18 & 70 & 19 & 76 \\
S2: Indicating limitations & 12 & 48 & 16 & 76 \\
S3: Evaluating methodology & 14 & 56 & 19 & 76 \\
\hline M3: Deductions from the research & 19 & 76 & 18 & 72 \\
\hline S1: Recommending future research & 17 & 68 & 16 & 64 \\
\hline S3: Drawing pedagogic implications & 14 & 56 & 6 & 24 \\
\hline
\end{tabular}

As can be seen from the frequency and percentage of moves, the general tendency of Move 1 in Economic Psychology subcorpus (100\%) is slightly higher than Applied Linguistics subcorpus (92\%). All the conclusions in Economic Psychology RAs were found to have employed summarizing the results move, whereas only 23 conclusions in Applied Linguistics RAs seemed to have employed the said move. Additionally, Move 2 also seemed to comprise a large proportion of conclusions in Applied Linguistics data (about 80\%) and Economic Psychology data (about 76\%). Table 6 displays that all three steps of Move 2 were employed in both data sets with a slight frequency difference. Step 1 (Indicating significance/advantages) was a slightly more preferred by Economic Psychology author (about 76\%) than Applied Linguistics authors (about 72\%). Similarly, the frequency of occurrence of step 2 (indicating limitations) and step 3 (Evaluating methodology) is found to be higher in Economic Psychology (about 64\% and 76\%) than Applied Linguistics conclusions (about 485 and 56\%).

Additionally, an examination of the move structure revealed a slight distinction in the occurrence of Move 3. (Deductions from the research). Although Move 3 was the third most frequent occurrence in both corpora, the percentage in the Economic Psychology sub-corpus is slightly lower than in the Applied Linguistics sub-corpus (about 72 percent and 76 percent respectively). Interestingly, while the authors of Applied Linguistics used both Step 1 (Recommending future research) and Step 2 (Drawing pedagogic implications) to accomplish this, the authors of Economic Psychology primarily used Step 1 to accomplish the research's conclusions. As shown in Table 6, 
Economic Psychology conclusions indicated that Step 2 in Move 3 had the lowest frequency (about 24 percent).

The second part of third research question is concerned about the similarities and differences in verb tense usage in the rhetorical structure of conclusion sections of both disciplines. The comparison between frequency and percentage of verb tenses in the moves of the present corpus is presented in Table 7.

Table No. 7 The comparison between overall frequency and percentage of verb tense usage in both data sets.

\begin{tabular}{|c|c|c|c|c|c|c|c|c|c|c|c|c|}
\hline \multirow[t]{3}{*}{ Moves } & \multicolumn{6}{|c|}{ Applied Linguistics } & \multicolumn{6}{|c|}{ Economic Psychology } \\
\hline & \multicolumn{2}{|c|}{ Present } & \multicolumn{2}{|c|}{ Past } & \multicolumn{2}{|c|}{ P.P } & \multicolumn{2}{|c|}{ Present } & \multicolumn{2}{|c|}{ Past } & \multicolumn{2}{|c|}{ P.P } \\
\hline & $\mathrm{F}$ & $\mathrm{P}$ & $\mathrm{F}$ & $\mathrm{P}$ & $\mathrm{F}$ & $\mathrm{P}$ & $\mathrm{F}$ & $\mathrm{p}$ & $\mathrm{F}$ & $\mathrm{p}$ & $\mathrm{F}$ & $\mathrm{P}$ \\
\hline Move 1 & 46 & 25.6 & 10 & 5.5 & 14 & 7.8 & 71 & 31.1 & 9 & 3.9 & 5 & 2.1 \\
\hline Move2 & 53 & 29.6 & 19 & 10.6 & 9 & 5.02 & 76 & 33.3 & 22 & 9.6 & 1 & 0.4 \\
\hline Step 1 & 26 & -- & 5 & -- & 1 & -- & 20 & -- & 2 & -- & 0 & -- \\
\hline Step 2 & 15 & -- & 10 & -- & 3 & -- & 27 & -- & 13 & -- & 0 & -- \\
\hline Step 3 & 12 & -- & 4 & -- & 5 & -- & 29 & -- & 7 & -- & 1 & -- \\
\hline Move 3 & 20 & 11.1 & 5 & 2.7 & 3 & 1.6 & 44 & 19.2 & 0 & -- & 0 & -- \\
\hline Step 1 & 10 & -- & 0 & -- & 1 & -- & 22 & -- & 0 & -- & 0 & -- \\
\hline Step 2 & 10 & -- & 5 & -- & 2 & -- & 22 & -- & 0 & -- & 0 & -- \\
\hline Total & $\begin{array}{l}11 \\
9\end{array}$ & 66.4 & 34 & 18.9 & 26 & 14.4 & 191 & 83.7 & 31 & 13.5 & 6 & 2.6 \\
\hline
\end{tabular}

Regarding the comparison of verb tense, the findings revealed that the preferred usage of tense patterns in each move of Economic Psychology RA conclusions is distinctive than that of Applied Linguistics RAs. After calculating the frequencies of verb tense in each move, the results unveiled a greater tendency of simple present tense being used by Economic Psychology authors than by Applied Linguistics authors. The analysis further showed that both the Applied Linguistics and Economic Psychology authors displayed the difference in frequency occurrence of the simple present tense in Move 1 (Summarizing the results) which is employed $25.6 \%$ and $31.1 \%$ respectively. This finding is consistent with Saboori and Hashemi's (2013) and Oster's (1981) findings that the simple present tense is the appropriate tense in which to present research findings. However, the overall percentile of simple past and present perfect tense in the said move seems to be relatively higher in Applied Linguistics data (5.5\% and 7.8\%) than in Economic Psychology data (3.9\% and 2.1\%).

Further analysis showed that though Move 2 (Interpreting the results) showed the greatest tendency of the simple present tense in both disciplines than other tenses; nonetheless, the frequency in Economic Psychology RAs (about 33.3\%) is found to be far greater than in Applied Linguistics RAs (about 29.6\%). Similarly, the presence of past tense in Move 2 by Economic Psychology authors is slightly frequent than Applied Linguistics authors. The findings disclosed that both the Applied Linguistics and Economic Psychology author did not seem to prefer interpreting their results in present perfect tense; however, its rate is slightly higher in Applied Linguistics conclusions (about $5.02 \%$ ) than in Economic Psychology conclusions (about 0.4\%).

Regarding the occurrence of Move 3 (Deductions from the research), it can be seen from Table 7 that although the utilization of simple present tense is prominent in the dataset, it is the Economic Psychology authors who tend to adhere to it more than Applied Linguistics authors. Economic Psychology authors use simple present tense considerably more frequently than Applied Linguistics authors (19.2\% Vs 11.1\%). The analysis showed that Economic Psychology authors seemed to have only unitized present tense while drawing deductions from the research as no other tense is found to be used to clarify the said move. While a smaller proportion of simple past and present perfect tense is found in Move 3 of Applied Linguistics conclusions.

On a thorough examination, the overall percentage of the simple present tense in Economic Psychology RAs is far greater than Applied Linguistics RAs (about 83.7\% and 66.4\% respectively). 
Although, both the disciplines pertain to soft sciences, Economic Psychology authors seem to utilize a greater number of the simple present tense in all three moves of the conclusion section than other tenses. However, the percentage of past tense and present perfect tense in Economic Psychology RAs (about $13.5 \%$ and $2.6 \%$ ) is seemingly far less than that of Applied Linguistics RAs (about $18.9 \%$ and $14.4 \%)$.

\section{DISCUSSION}

As mentioned previously, the primary objective of this study is to examine the rhetorical structure of RA conclusions from the perspectives of Applied Linguistics and Economic Psychology, as well as to determine whether there is any difference in the use of verb tense in the rhetorical organization of conclusion sections from two corpora. The present corpus revealed that Move 1 (Summarizing the results), which occurred at a frequency of $100 \%$ and $92 \%$ in all articles in Economic Psychology and Applied Linguistics, respectively, is regarded as a mandatory and conventional move in these disciplines. This creates the impression that the authors of these conclusions focused primarily on presenting the major objectives and summarizing the major findings. This finding is consistent with the findings of Ghazanfari et al., (2016), who concluded that Move 1 is a required and conventional move in the ELT and Nursing corpora, respectively. Morales (2012) also stated in support of this finding that Move 1 is a prominent and conventional move in Filipino and Japanese corpora. On the other hand, Moritz et al., (2008) conducted a study on the conclusion of RAs and discovered that Move 1 'Summarizing the study' is the least frequently occurring move in their study.

It is quite interesting that Move 2 (Evaluating the study) was also a recurrent move in both the Applied Linguistics and Economic Psychology corpora which was employed with the frequency of $80 \%$ and $76 \%$ respectively. It could be inferred that Move 2 was a conventional and significant move in the current study. This finding is not in accordance with Morales' (2012) study in which Move 2 was an obligatory move and step 1 (Indicating significance/advantages) was a frequent step. In another comparative study by Aslam and Mehmood (2014), this move was an optional move that only occurred in $20 \%$ and $40 \%$ in natural science and social science articles. The possible justification could pertain to the choice of different disciplines or the small size of our sample.

Another notable finding is that Move 3 (Deductions from the research) was also found to a conventional move as it was also employed with the frequency of $79 \%$ and $72 \%$ in Applied Linguistics and Economic Psychology corpora respectively. Consistent to our findings regarding Applied Linguistics conclusion, Morales' (2012) study found that Move 3 is a very prominent move which was significantly realized by both Step 1 (Recommending future research) and Step 2 (Drawing pedagogic implications). In Yang and Alison's (2003) study, this move was also found to be a substantial move and was extensively realized by Step 2, which is contrary to our findings regarding Economic Psychology sub-corpus as Move 3 was often realized by Step 1 (Recommending future research).

Another notable finding regarding the move pattern is that research articles of both the datasets employed Move 1 (Summarizing the study) as the opening move of conclusion sections. Almost all the authors opened their conclusions by presenting the main objectives or referring to background information. This finding is assumed to be in line with Amnuai and Wannaruk's (2013) findings who also found the said move as the opening move of half of the conclusion section of International RAs.

The study's findings regarding the prevalence of the tense type are quite intriguing. Both sets of data revealed a greater proclivity for using the simple present tense in Move 1 (Summarizing the study). This finding indicates that researchers in both disciplines preferred to present their findings in the present simple tense. This phenomenon could be explained by the fact that the results were validated and gained greater generalizability through the use of the simple present tense. This finding is consistent with Fallahi and Erzi's (2003) findings that the informational rhetorical unit, which was typically focused on the study's aims and objectives, was frequently discussed in the present simple tense. Additionally, Taylor (2001) discussed how the present simple tense can be used to clarify the study's objectives. Additionally, it implies that when the authors' findings are corroborated by prior research, they consolidated and generalized their findings by employing the simple present tense. 
Another noteworthy finding is that Move 2 (Evaluating the study) uses the present tense more frequently than any other tense. One of the numerous factors influencing the tense choice is the author's position and assertions made during the study's evaluation. As a result, the author's position on the evaluation of a portion of the result was primarily expressed in the simple present tense. This is supported by Weissberg and Buker (1990) and Desterji et al. (2017), who discovered that the simple present was the preferred tense for results interpretation. This also accords with the findings of Fallahi and Erzi (2003) who discovered that the present tense is preferred in $84 \%$ of sentences discussing the interpretation of results.

As far as Move 3 (Deductions from the research) is concerned, the results revealed a greater tendency to use present simple tense in present corpora. This finding confirms Swales and Feak's (2004, p.191) suggestion that "there is an increasing tendency to choose the present". However, it is also a notable result that Move 2 and Move 3 used relatively low frequency-or zero frequency in terms of Economic Psychology data - of simple past and present perfect tense which could be because authors tend to provide future recommendations and pedagogic implications with the help of other linguistic features i.e., modal verbs. Higher use of the modal verbs in this step can be explained by the fact that here authors evaluate their work in terms of its contribution to their field of inquiry, and therefore, they tend to avoid commitment or making bold statements. Further research may shed light on the issue. As for the small size of the corpus used in the present study, the findings are not deemed to be conclusive.

\section{CONCLUSION}

The present study aimed at investigating and analyzing the rhetorical structure of conclusion sections as well as verb tense employment in each move. It was a comparative study between Applied Linguistics and Economic Psychology disciplines. To fulfill this aim, the comparative analysis was carried out to discover possible similarities and differences in the structural moves and appropriate tense usage in RA conclusion sections of two disciplines. The findings of this study showed that both Applied Linguistics and Economic Psychology authors preferred Move 1 (Summarizing the results) and this move was found to be compulsory and conventional move in Economic Psychology and Applied Linguistic disciplines respectively. Economic Psychology authors also seem to prefer Move 1 more than AL authors as it occurred in all the research articles in Economic Psychology RAs. All the other moves in both data sets appear to be conventional. It also revealed that no move seemed to be an optional move in the present data.

By the information obtained from the tense analysis, the results indicated that the simple present tense was the most preferred tense in both sets of data. It was worth mentioning that the rate of present tense used in Economic Psychology is relatively higher than Applied Linguistics. While the Economic Psychology authors only seemed to prefer simple present tense to clarify Move 2 and Move 3 , AL authors also employed simple past and present perfect tense in order to evaluate the study and draw deductions from the research.

Like all the other previous work, this study also had some limitations. One of the limitations of the current study is the small size of the corpus. Only 50 research articles were analyzed in the present research. For further research, a large corpus could give several precise findings regarding the tense pattern in structural units of the conclusion sections. Also, this study was only limited to investigating the rhetorical structure and tense patterns in the conclusion section, while several other linguistic features like modal verb, hedging, and metadiscoursal features should also be analyzed in conclusion sections in future research. Moreover, this study was only bound to two disciplines of soft sciences. Cross-linguistics and cross-cultural analysis can be carried out by examining the use of verb tense and modal verbs in various other disciplines of soft and hard sciences or several other cultures.

From the pedagogical point of view, this study will help student writers in the employment of appropriate verb tense in particular moves and steps of the conclusion section. It will also provide helpful insights for the teachers of L2 language to pay proper attention to the conclusion writing, utilizing proper verb tense while summarizing their research. The findings of this study can prove helpful for the students and researchers in the field of EAP. Students can be taught how to write conclusions in certain disciplines following the correct conventions and norms of particular academic disciplines. Even the syllabus designers and EFL instructors can be able to get insightful information from the findings of our study. It should be noted that the same study could be conducted in other 
disciplines exploring the appropriate use of other linguistic markers in various moves of conclusion sections.

\section{REFERENCES}

Adel, S. M. R., \& Moghadam, R.G. (2015). A comparison of moves in conclusion sections of research articles in Psychology, Persian Literature and Applied Linguistics. Teaching English Language, 9(2), 167-191.

Amnuai, W., \& Wannaruk, A. (2013). A move-based analysis of the conclusion sections of research article published in international and Thai journals. 3L: Language, Linguistics, Literature, 19(2).

Aslam, I., \& Mehmood, A. (2014). Genre analysis of conclusion sections of Pakistani research articles in Natural and Social Sciences. Journal of Natural Sciences Research, 22(4), 106-112.

Bhatia, V. K. (1993). Analysing Genre: Language use in professional settings. London: Longman.

Brett, P. (1994). A genre analysis of the results section of sociology articles. English for Specific Purposes, 13(1), 47-49.

Bruce, I. (2008). Cognitive genre structures in methods sections of research articles: A corpus study.

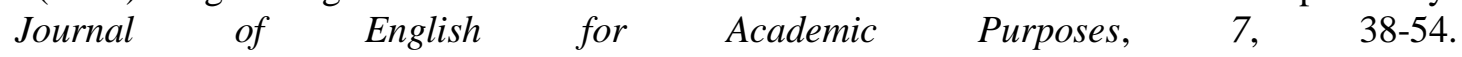
http://dx.doi.org/10.1016/j.jeap.2007.12.001

Creswell, J. W. (2009). Research design: Qualitative, Quantitative, and Mixed methods Approaches (3rd ed.). California, USA: SAGE

Darabad, A. M. (2016). Move analysis of research article abstracts: A cross-disciplinary study. International Journal of Linguistics, 8(2), 125-140.

Dastjerdi, Z.S., Tan, H., \& Abdullah, A. N. (2017). Tense analysis in rhetorical movement of results and discussion chapters of master's theses in hard sciences. Journal of Applied Linguistics and Language Research, 4(6), 1-18

Fallahi, M., \& Erzi, M. (2003). Genre analysis in language teaching: An investigation of the structure of the discussion section of language-teaching-journal articles. Iranian Journal of Applied Linguistics, 6(1), 69-81.

Fatma, K. A. Y. A., \& YAĞIZ, O. (2020). Move analysis of research article abstracts in the field of ELT: A comparative study. Journal of Language and Linguistic Studies, 16(1), 390-404.

Ghazanfari, M., Mohtasham, N.H., \& Amirsheibani, M. (2016). Genre analysis of nursing and ELT academic written discourse. Journal of Language Teaching and Research, 7(5), 973-978

Harwood, N. (2005). "I hoped to counteract the memory problem, but I made no impact whatsoever": discussing methods in computing science using I. English for Specific Purposes, 24, 243-267.

Hinkel, E. (1997). The past tense and temporal verb meanings in a contextual frame. TESOL Quarterly, 31(2), 289-313.

Kanoksilapatham, B. (2005). Rhetorical structure of biochemistry research articles. English for Specific Purposes, 24, 269-292

(2003). A corpus-based investigation of scientific research articles: Linking move analysis with multidimensional analysis. Georgetown University.

Li, L., Franken, M., \& Wu, S. (2020). Bundle-driven move analysis: Sentence initial lexical bundles in $\mathrm{PhD}$ abstracts. English for Specific Purposes, 60, 85-97

Morales, R. C. (2012). Conclusions in research articles: A Filipino-Japanese contrastive rhetorical study. Philippine ESL Journal, 8, 83-95.

Morit, M. E., Meurer, J. L., \& Dellagnelo, A. K. (2008). Conclusions as components of research articles across Portuguese as a native language, English as a native language and English as a foreign language: a contrastive genre study. The Especialist, 29, 233-253.

Nwogu, K. N. (1997). The medical research paper: Structure and functions. English for Specific Purposes, 16, 119-138

Oster, S. (1981). The use of tenses in reporting past literature. In Selinker, L., E. Tarone \& V. Hanzeli (Eds.), English for Academic and Technical Purposes: Studies in Honour of Louis Trimble, (pp. 76-90). Newburg House, Rowley, Massachussetts.

Özturk, İ. A function-first approach to verb tense usage in research article introductions in applied linguistics. Dil Dergisi, 170(2), 31-53. 
Peacock, M. (2002). Communicative moves in the discussion section of research articles. System, 30, 479-497.

Posteguillo, S. (1999). The schematic structure of computer science research articles. English for Specific Purposes, 18, 139-160.

Saboori, F., \& Hashemi, M. R. (2013) A cross-disciplinary move analysis of research Article abstracts. International Journal of Language Learning and Applied Linguistics World, 4(4), 2289-3245.

Salager-Meyer, F. (1992). A text-type tense and move analysis study of verb tense and modality distribution in medical English Abstracts. English for Specific Purposes, 11, 93-113.

Samraj, B. (2002). Introductions in research articles: Variations across disciplines. English for Specific Purposes, 21, 1-17

Swales, J. M. (1990). Genre analysis: English in academic and research settings. Cambridge, UK: Cambridge University Press.

(2004). Research genres: Explorations and applications. Cambridge, UK: Cambridge University Press.

Swales, J. M., \& Feak, C. B. (1994). Academic writing for graduate students: Essential tasks and skills-A course for nonnative speakers of English. Ann Arbor MI: University of Michigan Press.

Taylor, G. (1989). The student's writing guide for the arts and social sciences. Cambridge: Cambridge University Press.

Thomas, S., \& Hawes, T. P. (1994). Reporting Verbs in Medical Journal Articles. English for Specific Purposes, 13, 129-148.

Tseng, F. P. (2011). Analyses of move structure and verb tense of research article abstracts in applied linguistics. International Journal of English Linguistics, 1(2), 27-39.

Weissberg, R., \& Buker, S. (1990). Writing up research: Experimental research report writing for students of English. Englewood Cliffs, NJ: Prentice Hall Regents.

William, I. A. (1999). Results sections of medical research article: Analysis of rhetorical categories for pedagogical purposes. English for Specific Purposes, 18(4), 347- 366.

Yang, R., \& Allison, D. (2003). Research articles in applied linguistics: Moving from results to conclusions. English for Specific Purposes, 22, 365-385

Zand-Moghadam, A., \& Mihami, H. (2016). A rhetorical move analysis of TEFL thesis abstracts: The case of Allameh Tabataba'i University. Issues in Language Teaching, 5(1), 1-23. 